\title{
Treatment of COPD and the TOnado trial: a tempest in a teapot?
}

\author{
Klaus F. Rabe \\ Affiliations: LungenClinic Grosshansdorf, Airway Research Center North, Member of the German Center for Lung \\ Research (DZL), Grosshansdorf, Germany. Department of Medicine, Christian Albrechts University, Airway
} Research Center North, Member of the German Center for Lung Research (DZL), Kiel, Germany.

Correspondence: Klaus F. Rabe, Lungen Clinic Grosshansdorf Germany, Woehrendamm 80, D-22927 Grosshansdorf, Germany. E-mail: k.f.rabealungenclinic.de

0 @ERSpublications

Despite encouraging results for LABA/LAMA combination therapy in mild COPD, can we justify the additional costs? http://ow.ly/JVNb6

The treatment of COPD follows a stepwise approach in practically all clinical practice guidelines and also current strategy documents [1]. Lung function impairment or low forced expiratory volume in $1 \mathrm{~s}$ (FEV1), once considered the single most important treatment parameter, now represents one of the target parameters for risk reduction in patients with chronic obstructive pulmonary disease (COPD), alongside exacerbations and respiratory symptoms, dyspnoea in particular. Furthermore, more holistic COPD approaches increasingly recognise the importance of physical activity and multimorbidity for disease outcome, mortality in particular [2].

Long-acting bronchodilators, such as long-acting muscarinic antagonists (LAMAs) and long-acting $\beta_{2}$-adrenoceptor agonists (LABAs) are the cornerstone of maintenance therapy for patients with moderate-to-severe COPD whose symptoms are not adequately controlled by short-acting bronchodilators alone $[1,3]$. The crucial role of these drugs has, in part, been helped by the fact that long-acting bronchodilators, and LAMAs in particular, have demonstrated efficacy in preventing COPD exacerbations, a good safety record and might even decrease mortality $[4,5]$. Also, the role of inhaled steroids for chronic treatment remains controversial and largely unresolved, despite recent efforts to identify a COPD phenotype that might benefit from this form of treatment [6].

Since anticholinergic drugs and $\beta_{2}$-adrenoceptor agonists differ in their pharmacology and their target receptors, but both act on the level of airway smooth muscle tone, combinations of these drug classes have been used and have been advocated for the treatment of COPD for decades. It comes therefore with little surprise that also the combination of LAMA and LABA is recommended for COPD patients not adequately controlled on a single bronchodilator drug alone [1] resulting in the development of an increasingly confusing variety of LAMA+LABA fixed-dose combinations (FDCs), and their respective generic clones [3].

In the current issue of the European Respiratory Journal, a novel candidate of this drug combination principle is presented by BuHL et al. [7]. Two replicate phase III trials aimed to assess the efficacy and safety of inhaled tiotropium+olodaterol FDC $5 / 5 \mu \mathrm{g}$ or $2.5 / 5 \mu \mathrm{g}$ delivered via the Respimat Soft Mist inhaler compared with their individual mono-components in patients with moderate-to-very-severe COPD (Global Initiative for Chronic Obstructive Lung Disease stage 2-4) over 52 weeks. The authors hypothesised that combination therapy with tiotropium+olodaterol FDC would provide improvements in lung function, health-related quality of life (St George's Respiratory Questionnaire (SGRQ) total score at 24 weeks) and other COPD disease parameters compared to monotherapy with either component alone, and with a comparable safety profile.

Received: Feb 172015 | Accepted after revision: Feb 182015

Conflict of interest: Disclosures can be found alongside the online version of this article at erj.ersjournals.com

Copyright @ERS 2015 
Tiotropium is an established once-daily LAMA that improves lung function and several patient-orientated outcomes of COPD, and has also been suggested to moderate disease progression in milder forms of COPD [8-11]. A novel LABA, olodaterol, is highly selective and a near full agonist at $\beta_{2}$ receptors providing 24-h bronchodilation in patients with COPD. Preliminary data suggest that olodaterol might also afford symptomatic benefit and enhanced exercise capacity [12-14].

The presented study is of good quality and is large, with a total of 5162 patients in both trials analysed together. Both FDCs significantly improved FEV 1 area under the curve from 0 to $3 \mathrm{~h}$ and trough FEV 1 response versus the respective mono-components in both studies. Statistically significant improvements in SGRQ total score versus the mono-components were only seen for the higher dose of tiotropium +olodaterol FDC $(5 / 5 \mu \mathrm{g})$ and the clinical significance of the reported absolute difference can be debated. Incidence of adverse events was comparable between the FDCs and the mono-components. These studies, therefore, primarily demonstrated significant improvements in lung function, and to a lesser degree and only some improvement of health-related quality of life with once-daily tiotropium+olodaterol FDC compared with the mono-components over 1 year.

The authors suggest that their study has several limitations. The lack of a placebo group is mentioned but probably inevitable since for this patient group of symptomatic COPD patients it seems indeed inappropriate to deny the use of long-acting bronchodilator for 1 year. What is likely of more relevance is the choice of endpoint, and the fact that exacerbations were not analysed, despite the size of the population and duration of the trial. The reader is somewhat reassured that this information will be available at some stage through other trials although unfortunately no firm date or details are given.

Acronyms of study protocols are becoming a real nuisance in the opinion of this editorialist and probably only clinical trial aficionados can remember all abbreviations plus those of the respective drugs and the increasing number of inhaler devices each of them with a fantasy name of their own. Tornare in Spanish means "to turn" and this probably led the designers of the present trial to think that TOnado will ring a bell in the mind of the reader since it is mainly about increasing volume of air. However, it remains unclear at present whether the findings are indeed a turning point. Sure, at the very least, the present novel drug combination shows higher efficacy on the endpoints of the study compared with the mono-components but what we really want to know is whether this drug combination will affect (severe) exacerbations and hospitalisations, and ultimately death. With the predictable development of more and similar drug combinations, these endpoints are ultimately of great relevance. In October 2014, the German Institute for Quality and Efficiency in Health Care, for example, already questioned the additional benefit of one such combination (umeclidinium/vilanterol (Anoro)), over the comparator tiotropium, in more severe disease, which might have consequences for drug reimbursement for the class of drug combinations in general in the future.

Like earlier studies on bronchodilators in COPD, the present trial is again somewhat blurred by the fact that almost $50 \%$ of patients were on inhaled corticosteroids despite the relatively mild disease severity of the population, and almost $10 \%$ were on xanthines. The well-documented efficacy of the LAMA tiotropium in COPD at least on lung function is clearly further helped by the addition of olodaterol in this drug combination, as demonstrated by the present trial. Whether this in its own right is sufficient as maintenance therapy without any other anti-inflammatory treatment remains to be seen, and studied. The very latest result from yet another study with an acronym (REACT) might challenge this proposition as it suggests that phosphodiesterase- 4 inhibition further increases lung function and affects severe exacerbations and hospitalisations in patients on triple therapy including LAMA and LABA and ICS [15]. Despite the encouraging results of the trial by BuHL et al. [7] for the treatment of mild disease we have to justify additional costs of LAMA/LABA combinations eventually and, for severe COPD, we are not there yet.

\section{References}

1 Global Initiative for Chronic Obstructive Lung Disease. Global strategy for the diagnosis, management, and prevention of chronic obstructive pulmonary disease. Available from www.goldcopd.org/uploads/users/files/ GOLD_Report2014_Feb07.pdf Date last updated: February 7, 2014. Date last accessed: February 19, 2015.

2 Waschki B, Kirsten A, Holz O, et al. Physical activity is the strongest predictor of all-cause mortality in patients with COPD: a prospective cohort study. Chest 2011; 140: 331-342.

3 Tashkin DP, Ferguson GT. Combination bronchodilator therapy in the management of chronic obstructive pulmonary disease. Respir Res 2013; 14: 49.

4 Tashkin DP, Celli B, Senn S, et al. A 4-year trial of tiotropium in chronic obstructive pulmonary disease. $N$ Engl J Med 2008; 359: 1543-1554.

5 Vogelmeier C, Hederer B, Glaab T, et al. Tiotropium versus salmeterol for the prevention of exacerbations of COPD. N Engl J Med 2011; 364: 1093-1103.

6 Magnussen H, Disse B, Rodriguez-Roisin R, et al. Withdrawal of inhaled glucocorticoids and exacerbations of COPD. N Engl J Med. 2014; 371: 1285-1294.

7 Buhl R, Maltais F, Abrahams R, et al. Tiotropium and olodaterol fixed-dose combination versus mono-components in COPD (GOLD 2-4). Eur Resp J 2015; 45: 969-979. 
8 Yohannes AM, Willgoss TG, Vestbo J. Tiotropium for treatment of stable COPD: a meta-analysis of clinically relevant outcomes. Respir Care 2011; 56: 477-487.

9 Wise RA, Anzueto A, Cotton D, et al. Tiotropium Respimat Inhaler and the risk of death in COPD. N Engl J Med 2013; 369: 1491-1501.

10 Troosters T, Celli B, Lystig T, et al. Tiotropium as a first maintenance drug in COPD: secondary analysis of the UPLIFT $^{\circledast}$ trial. Eur Respir J 2010; 36: 65-73.

11 Decramer M, Celli B, Kesten S, et al. Effect of tiotropium on outcomes in patients with moderate chronic obstructive pulmonary disease (UPLIFT): a prespecified subgroup analysis of a randomised controlled trial. Lancet 2009; 374: 1171-1178.

12 Bouyssou T, Casarosa P, Naline E, et al. Pharmacological characterization of olodaterol, a novel inhaled $\beta_{2}$-adrenoceptor agonist exerting a 24-hour-long duration of action in preclinical models. J Pharmacol Exp Ther 2010; 334: 53-62.

13 Casarosa P, Kollak I, Kiechle T, et al. Functional and biochemical rationales for the 24-hour-long duration of action of olodaterol. J Pharmacol Exp Ther 2011; 337: 600-609.

14 Lange P, Aumann J-L, Derom E, et al. The 24-h FEV1 time profile of olodaterol QD delivered via Respimat ${ }^{\circ}$ in COPD: Results from two 6-week studies. Eur Respir J 2013; 42: Suppl. 57, 982s.

15 Martinez FJ, Calverley PMA, Goehring UM, et al. Effect of roflumilast on exacerbations in patients with severe chronic obstructive pulmonary disease uncontrolled by combination therapy (REACT): a multicentre randomised controlled trial. Lancet 2015; [In press DOI: 10.1016/S0140-6736(14)62410-7]. 